
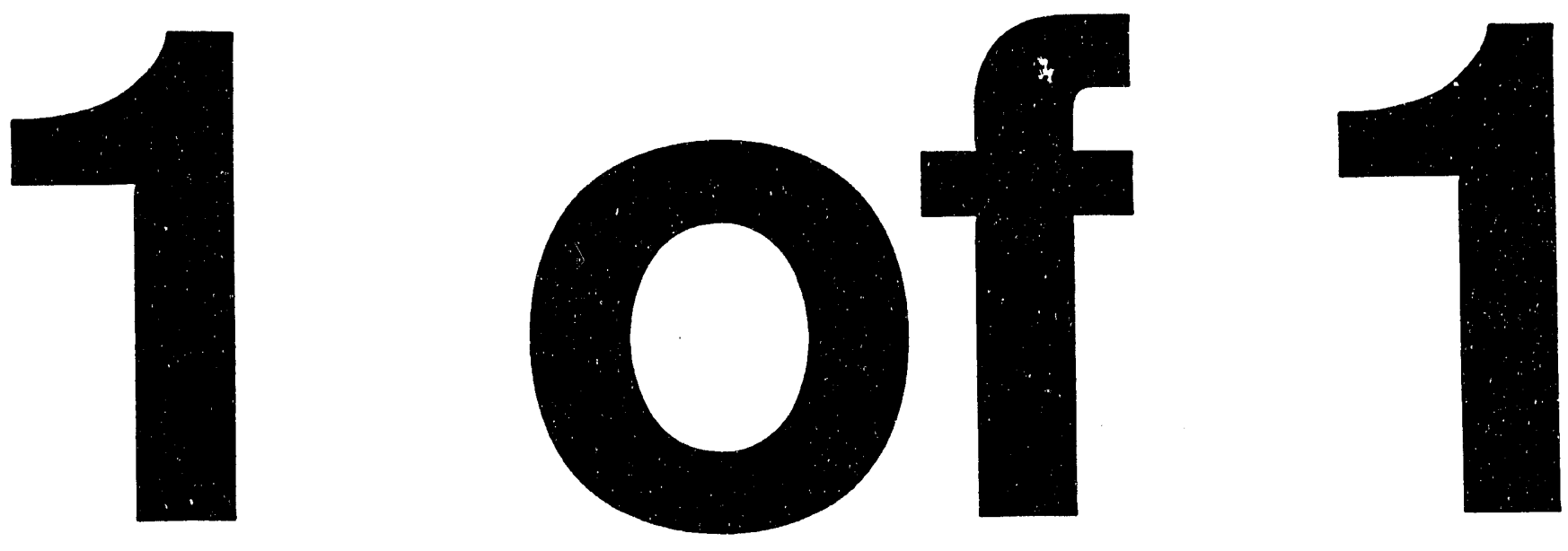


\section{Department of Energy \\ Washington, DC 20585}

August 1994

TO:

FROM:

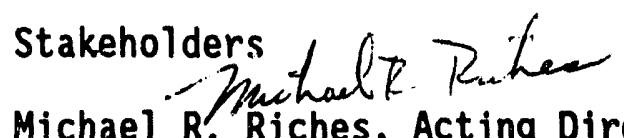
Division, Office of Health and Environmental Research, Office of Energy Research

The Department of Energy (DOE) has traditiona?ly supported long-term interdisciplinary studies in ocean science as part of its concern for sustainable development and on the dispersal and fate of energy-related materials (including $\mathrm{CO}_{2}$ ) in the marine environment. Presently, we are supporting strategic research for understanding ocean-atmosphere-climate interactions and the global carbon cycle. Our Ocean Margins Program (OMP) is a major component of this research effort, and its goals are to:

- Quantify the biogeochemical and ecological processes and mechanisms that affect the transformation, flux, and storage of carbon at the land/ocean interface;

- Define ocean-margin sources and sinks in the global carbon cycle; and

- Determine whether continental shelves are quantitatively significant in removing carbon dioxide from the atmosphere and isolating it via burial in sediments or by export into the interior ocean.

Our OMP approach has been to support both process-oriented research to understand the physical, biogeochemical, plant, animal, and microbial interactions in coastal waters and sediments; and the development of new instrumentation to obtain high frequency in-situ measurements of the environmental and biological factors affecting carbon fluxes in the ocean. Recently, the DOE launched a new molecular biology initiative within its OMP to provide a mechanistic understanding of the complex biological processes which mediate the carbon cycle in marine systems. Molecular biological techniques are being developed, adapted, and applied to determine how biological processes are regulated and controlled by genetic limitations and environmental variables.

This program is fully integrated with the National Science and Technology Council's Committee on Environment and Natural Resources, as a focussed effort within the Subcommittee on Global Change Research and as a contributory effort within the Subcommittee on Water Resources and Coastal and Marine Environments. As the major U.S. integrated multidisciplinary research effort for understanding the ocean margin's role in the global carbon cycle, the OMP is strongly linked with the Joint Global Ocean Flux Study and the Global Ocean Ecosystems Dynamics Program within the U.S. Global Change Research Program. The OMP and its scientific researchers are also interacting with the Land-Ocean Interactions in the Coastal Zone Program within the International Geosphere-Biosphere Programme, and with several U.S.

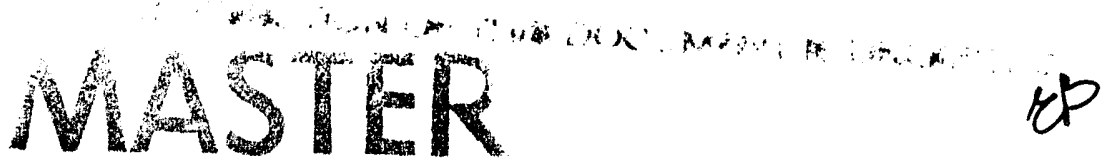


agency programs concerned with: (i) predicting the dispersal and fate of carbon, nutrients, contaminants, and sediments in coastal waters, (ii) quantifying primary productivity and ecological dynamics (structure and function) in ocean-margin systems, and (iii) examining the impacts of resource recovery and utilization in coastal areas. As a result, the quantitative information that is being obtained within OMP underpins policy decisions on living and non-living resource management in changing coastal areas. 


\title{
DEPAR'TMENT OF ENERGY
}

\section{OCEAN MARGINS PROGRAM}

\author{
Closure on the Global Carbon Cycle
}

\section{PROGRAM DESCRIPTION}

\author{
Sponsored by
}

The Office of Health and Environmental Research

\author{
Edited by
}

The Ocean Margins Program Steering Committee

August 1994 


\title{
A DESCRIPTION OF THE U.S. DEPARTMENT OF ENERGY
}

\section{OCEAN MARGINS RESEARCH PROGRAM}

\section{CLOSURE ON THE GLOBAL CARBON CYCLE}

\author{
Executive Summary: Program Description
}

The Department of Energy's Ocean Margins Program (OMP) is designed to quantitatively assess the importance of coastal ocean systems in the global carbon cycle. Since the beginning of the Industrial Revolution, human energy-related activities have dramatically altered the global carbon cycle, and consequently, this cycle is not presently in a steady-state. To reduce major uncertainties in predicting future global environmental quality, it is imperative to understand the sources and sinks of atmospheric $\mathrm{CO}_{2}$, the role of anthropogenic activities in disrupting the natural carbon cycle, and the effects of, and feedbacks between, these activities and the natural carbon cycle. Due to continuously increased loading of nutrients to the margins, which, globally, is related to the rate of human population growth and high population densities in coastal states, biological carbon fixation has been stimulated. Depending on the fate of the fixed carbon, this stimulation has the potential to mitigate the anthropogenically derived $\mathrm{CO}_{2}$. Determining the factors that control the magnitude of carbon exchanges between the ocean margins and the atmosphere, and the subsequent fate of this carbon, is crucial to predicting the strength and capacity of the oceans to absorb excess anthropogenic atmospheric $\mathrm{CO}_{2}$.

The first phase of the OMP broadly examines the continental margin of the western North Atlantic Ocean, which adjoins the east coast of the United States, focussing primarily on the southern portion of the Mid-Atlantic Bight between Cape Hatteras and Chesapeake Bay. In this region, a large flux of freshwater and particulate organic carbon flows to the North Atlantic Ocean. An interdisciplinary research team, using state-of-the-art physical, chemical, biologi$\mathrm{cal}$, and molecular tools, will trace and quantify the fluxes and fate of carbon in the coastal ocean. The program elements, which include geochemical tracers, physical circulation, biological and molecular ecological processes, will be used to understand if, and how, the continental margin serves as a conduit to transfer atmospheric $\mathrm{CO}_{2}$ to the deep ocean and sea floor. In addition to providing information that is necessary for assessing the importance of coastal-ocean systems in the global carbon cycle, this program will help provide the scientific framework necessary' for managing coastal ecosystems and energy resources. As a result, research efforis within DOE's OMP involve several Subcommittees of the National Science and Technology Council's (NSTC) Committee on Environment and Natural Resources (CENR), including Global Change, Water Resources, Coastal and Marine Environment, Biodiversity and Ecosystem Research, Resource Use and Depletion Research, and Global Observations. 


\section{Table of Contents}

Page

The Role of the Ocean Margins in the Global Carbon Cycle . . . . . . . . . . . .

The Continental Margin Paradigm $\ldots \ldots \ldots \ldots \ldots \ldots \ldots \ldots \ldots \ldots$

Uncertainties and Closure in the Global Carbon Cycle . . . . . . . . . . . . 3

The Role of DOE in the Global Carbon Cycle $\ldots \ldots \ldots \ldots \ldots$

The Ocean Margins Program - Phase I - The Western North Atlantic Experiment . . . . . 4

Experimental Approaches to Constraining the Continental Margin Carbon Cycle . . . . . 5

Molecular Biological and Biophysical Measurements in OMP . . . . . . . . . . 9

Pools and Flux Measurements: Organism to Ecosystem . . . . . . . . . . . . . . 10

Geochemical and Biogeochemical Processes: The Integrated System . . . . . . . . 11

Field Techniques . . . . . . . . . . . . . . . . . . . . . 12

Sampling and the Problems of Temporal and Spatial Heterogeneity . . . . . . . . 12

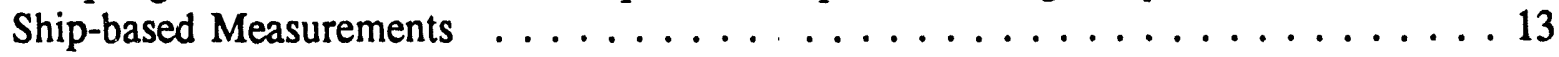

Observations from Continuous Moored Instruments . . . . . . . . . . . 13

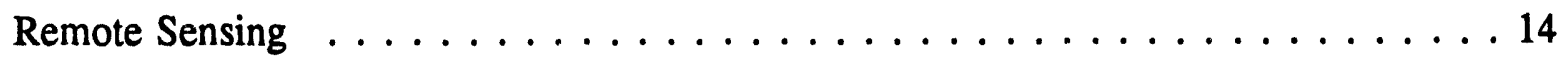

Integration of Information $\ldots \ldots \ldots \ldots \ldots$

Relationship to Other Ocean and Global Change Programs $\ldots \ldots \ldots \ldots$

Significance of OMP to Understanding the Global Carbon Cycle $\ldots \ldots \ldots$ 


\section{PROGRAM RATIONALE}

The Role the Ocean Margins in the Global Carbon Cycle

Since the beginning of the 20th century, the human population has increased from 1.5 to over 5 billion, and the concomitant increase in energy extraction and use has dramatically perturbed the natural biogeochemical cycle of key elements, especially carbon. With the approach of the 21 st century and with the projected population expansion, developing an integrated assessment of the potential effects of human activities on the Earth's environment has become increasingly urgent. The Earth is rapidly deviating from the quasi steady-state that has existed for the past 10,000 years. Energyrelated activities have directly altered the composition of the atmosphere, potentially affecting the radiative balance of the Earth, and have stressed many natural renewable resources. Such drastic changes cannot continue indefinitely without leading to irreversible and potentially adverse, disruptive effects on the economic security and social stability of the world.

One of the most important natural resources for U.S. economic and societal welfare is the continental ocean margin. The land/ocean interface forms a direct boundary for 23 states and is vital for commerce, food, energy resources and military security. By connecting the rivers to the ocean, the continental margins serve as a conduit for freshwater flow from the nation's interior to the open ocean. Consequently, the coastal regions receive the contaminated, eutrophied effluents from the industrial and agricultural heartland of the country. This drainage of inland water has profound effects upon the chemistry of suspended and particulate materials in the coastal ocean, and modifies the structure and dynamics of the physical environment. The total discharge of freshwater into the global coastal ocean has decreased by $15 \%$ during the past 30-40 years, while the average nitrogen concentration in the world's rivers has increased linearly with human population growth. Such nutrient loading has led to long-term changes in the global carbon cycle.

A major goal for the U.S. Department of Energy is to quantitatively assess the importance of the ocean margins in the global carbon cycle, and the effects of, and feedbacks between, the continent-ocean boundary and the Earth's climate.

\section{The Continental Margin Paradigm}

The exchange of $\mathrm{CO}_{2}$ between the atmosphere and the ocean amounts to approximately 100 gigatons $\left(1 \mathrm{GT}=10^{9}\right.$ tons) $\mathrm{C}$ per annum, which is approximately 15 times greater than that generated annually by anthropogenic activities. Net $\mathrm{CO}_{2}$ fluxes are primarily governed by the difference in partial pressure in $\mathrm{CO}_{2}$ across the air-sea interface. In surface waters, photosynthesis can convert aqueous $\mathrm{CO}_{2}$ into organic compounds, thereby reducing $\mathrm{CO}_{2}$ concentrations and facilitating the flux of atmospheric $\mathrm{CO}_{2}$ across the air-sea interface. Some fraction of the organic matter produced in the upper ocean sinks to the ocean depths and becomes oxidized by heterotrophic respiration, thereby enriching the deep ocean in inorganic carbon. This enrichment process, called the "biological pump", continuously strips $\mathrm{CO}_{2}$ from the surface ocean that is in contact with the atmosphere, and sequesters it in deeper water masses where it cannot directly exchange with the atmosphere. Thus, the biological pump acts to remove $\mathrm{CO}_{2}$ from the atmosphere. How- 
ever, an input of essential plant nutrients, such as nitrogen and phosphorus, is required to sustain photosynthetic carbon fixation in the upper ocean.

In the open ocean, these nutrients are supplied primarily from deep waters. The ratio of the carbon fixed to the essential plant elements is highly constrained in marine ecosystems, and hence, the downward flux of organic carbon is balanced by an upward flux of nitrogen and phosphorus. The fraction of carbon which can be exported to depth in the steady-state is constrained by the upward vertical flux of nitrogen as nitrate. The structure of the open ocean is primarily vertical, with upward and downward fluxes of carbon and essential plant nutrients constrained by the vertical mixing in the upper ocean. Moreover, the upward flux of nitrate is accompanied by an upward flux of $\mathrm{CO}_{2}$; on average, the ratio of these two soluble constituents is identical to the ratio of their incorporation into plant biomass. Hence, unless nutrients are added from sources external to the ocean, the biological pump has no net effect on the uptake of anthropogenically produced $\mathrm{CO}_{2}$.

Continental margins receive nutrients laterally from the deep ocean, primarily due to coastal upwelling. Upwelling can stimulate primary production and lead to an export and sequestration of organic carbon; in regions of intense upwelling, such as off the coast of Southwest Africa and Peru, organic carbon concentrations in the sediments can approach $20 \%$ of the total dry mass of the sediments. While upwelling systems are extremely important for fisheries, in and of themselves they do not provide a conduit for the uptake of anthropogenic $\mathrm{CO}_{2}$ because the ratio of nitrate to $\mathrm{CO}_{2}$ in the upwelling waters is, on average, identical to the ratio of the two nutrients in the fixed organic matter. However, unlike the open ocean there is a second major source of nutrients to the continental margins, namely terrestrial run-off.

Before the Industrial Revolution, there was only minor enrichment of the continental margins from anthropogenic activities. However, throughout the 20th century, the increased application of fertilizers and production of sewage rose exponentially, and consequently, greatly enriched the ocean margins with a new source of nutrients [Figure 1; after Peierls et al., Nature 350: 386 (1991)]. Moreover, because the water

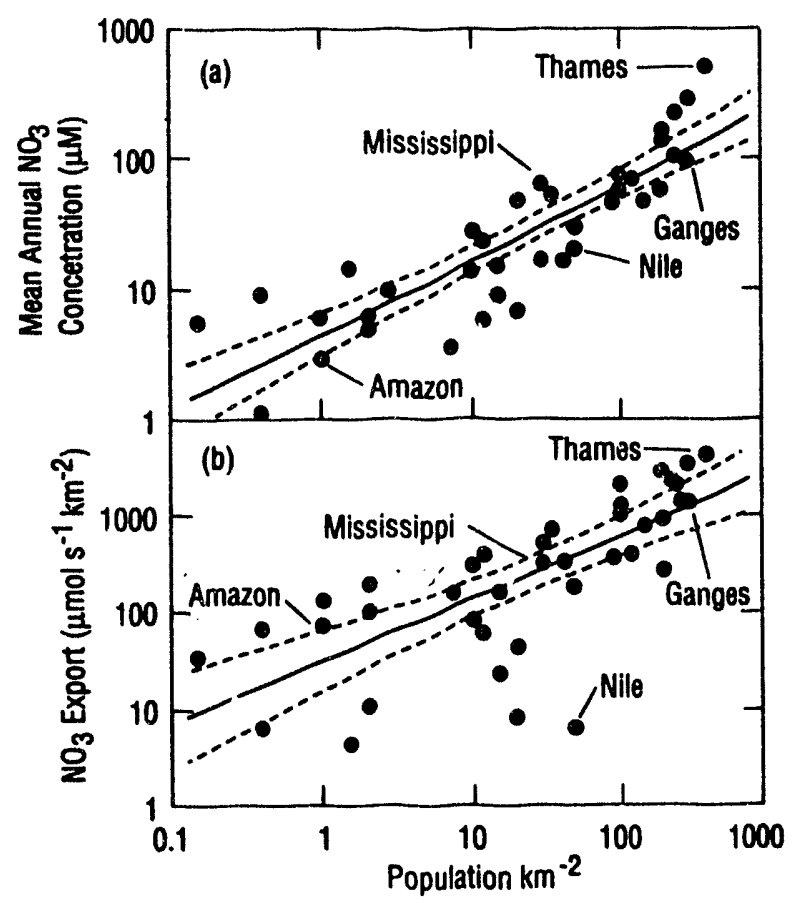

Figure 1. The relationship between (a) the annual mean nitrate concentration and (b) total nitrate export and population densities for $\mathbf{4 2}$ rivers in the world [after Peierls et al., Nature 350: 386 (1991)]. Each point represents a different river; some major rivers are labelled. The solid lines are regressions while the dashed lines are the $95 \%$ confidence intervals. These data reveal a high correlation between human population growth and nutrient loading to the coastal oceans. 
column on continental margins is relatively shallow, nutrients in the sediments can be recycled relatively rapidly, thereby allowing much more efficient use of the nutrients (i.e., there is no large reservoir of unused nutrients, as in the deep ocean basins). The magnitude and fate of this net new production are unknown.

\section{Uncertainties and Closure in the Global Carbon Cycle}

In the mid-1970s, it became apparent that the increase in atmospheric $\mathrm{CO}_{2}$ is significantly less than the $\mathrm{CO}_{2}$ added to the atmosphere as a result of human activities. For over a deeade, most geochemists assumed that the sink for the missing $\mathrm{CO}_{2}$ was the ocean, which can absorb the gas by diffusion across the air-sea interface. This view was challenged by Tans et al. in $1990^{1}$, who suggested that the major sink is terrestrial photosynthesis at high latitudes, based on the latitudinal gradient in the $\mathrm{CO}_{2}$ concentrations. In 1992, Falkowski and Wilson ${ }^{2}$ concluded that while open-ocean production has remained relatively constant throughout the 20th century (and therefore, the biological pump in the open ocean plays a relatively small role in sequestering anthropogenic $\mathrm{CO}_{2}$ ), ocean margins are potentially a significant sink for the missing carbon. The debate over whether the nonbiological uptake of $\mathrm{CO}_{2}$ by the oceans is more significant than terrestrial photosynthetic sequestration can potentially be resolved by analyses of atmospheric $\mathrm{O}_{2}$. In abiotic, diffusive uptake of $\mathrm{CO}_{2}, \mathrm{O}_{2}$ is not produced, while photosynthetic $\mathrm{CO}_{2}$ fixation leads to a stoichiometric increase in $\mathrm{O}_{2}$. Careful measurements of changes in atmo-

\footnotetext{
${ }^{1}$ Tans, P.P., Fung, I. and Takahashi, T. 1990. Science 247: 1431.

${ }^{2}$ Falkowski, P.G. and Wilson, C. 1992. Nature 358: 741.
}

spheric $\mathrm{O}_{2}$ and the isotope ratios of $\mathrm{O}_{2}$ indicate that photosynthetic processes are a major sink for the anthropogenic $\mathrm{CO}_{2}$. Where is that sink -- on land, on the continental margins, or both?

The world's most productive ecosystems occur at the land/water interface. On a geological time scale, these wetland, ocean-margin, and shallow sea areas have served as major reservoirs for organic carbon and energy resources. Recent increases in nutrient fluxes to modern ocean-margin systems have caused them to deviate from steady-state, potentially creating an important sink for anthropogenic $\mathrm{CO}_{2}$ that critically depends upon eutrophication and nutrient additions from human activities. Ironically, attempts to improve water quality in rivers and estuaries which drain into the continental ocean margins may actually lead to an increase in atmospheric $\mathrm{CO}_{2}$.

Therefore, it is critical to the future energy and environmental policy of the world in general, and the United States in particular, to understand the role of ocean margins in the global carbon cycle. This understanding is a prerequisite for resolving the carbon cycle problem and for formulating a rational policy that benefits from objective scientific research.

\section{The Role of DOE in the Global Carbon Cycle}

The Department of Energy has a long history of supporting interdisciplinary studies of carbon cycling in coastal ocean systems as part of its concern about the dispersal and fate of energy-related materials in the environment. This history started in the mid-1940s from the idealistic vision of American scientists to harness nuclear- and 
defense-related expertise for peaceful purposes. For example, throughout the $1950 \mathrm{~s}$ and 1960s, DOE and its predecessor agencies pioneered the use of natural, bombgenerated, and tracer radiocarbon to understand ocean circulation, the factors controlling photosynthetic carbon fixation, and the fate of carbon in the sea. These early successes led DOE to establish the first multidisciplinary research teams in oceanographic sciences, which conducted regional studies along the U.S. continental shelves. These studies are a continuing model for the simultaneous use of moored instrumentation, shipboard sampling, and remote sensing, to measure movements of water masses, spatial and temporal concentrations of chemical species and particles, biological productivity and food-chain dynamics, and biogeochemical fluxes. Moreover, these research programs were the training ground for many marine scientists, whose efforts led to the development of many of the classical paradigms for understanding the role of the ocean in global biogeochemical cycles and climate.

The necessity for understanding earthsystem science and the effects of energyrelated activities on the future environment is as real today as it was at the end of World War II. However, today DOE and the world face new challenges to the environment, chief among which is the buildup of carbon dioxide and other greenhouse gases in the atmosphere, and their potential for altering global climate. To meet this challenge, DOE recently restructured its regional coastal-ocean programs into a new, integrated, multidisciplinary OMP.

The goals of the OMP are to:

- quantify the ecological and biogeochemical processes and mechanisms that define the cycling, flux, and storage of carbon and other biogenic elements at the land/ocean interface;

- identify how ocean-margin sources and sinks of carbon change in response to human activities; and

- determine whether continental shelves are quantitatively significant in removing atmospheric carlon dioxide and isolating it via burial in sediments or export to the interior of the open ocean.

The Ocean Margins Program - Phase I The Western North Atlantic Experiment

The region of the U.S. continental margin most impacted by humans is the eastern seaboard, which adjoins the Western North Atlantic Ocean. 'This region, consisting of the Middle and South Atlantic Bights and several coastal estuaries including Chesapeake Bay, receives the freshwater flow and effluents from 100 million people. In this region, the cumulative nutrient loading has demonstrably stimulated high levels of primary production; however, the fate of the excess production is not well understood. Carbon concentrations in the sediments off Cape Hatteras range from 2 to $4 \%$ of the dry weight, amongst the highest in the Western North Atlantic. Near-shore waters in this region are affected by 2 ? estuarine circulation pattern which pron s a net landward transport of particulate organic carbon (POC) along the bottom. Chesapeake Bay and other coastal estuaries are traps for nutrients and biologically assimilated carbon, and are sites of rapid organic carbon accumulation. Shelf waters from the Middle and South Atlantic Bights also converge in this region near Cape Hatteras and empty into the Western North Atlantic. As a result, carbon is exported into the interior ocean as dissolved organic carbon (DOC) or 
buried as POC in the sediments of the continental slope (Figure 2). Upwelling along the North Wall of the Gulf Stream off Cape Hatteras, together with the export of net new production of carbon from the continental margin of the east coast of the United States, provides a flux of carbon to the sediments of the continental slope of the Western North Atlantic. One way to assess the magnitude and fate of net new production is to budget oxygen. The burial and sequestration of net new production is inversely related to tive rate at which reduced carbon is oxidized. Oxygen has only two sources, in situ production from photosynthesis, or exchange with the atmosphere. It has two sinks, respiration and exchange with the atmosphere. Time-series records of dissolved oxygen can be used, in conjunction with measurements of the movement of water masses, to assess atmospheric gas exchange (Figure 3). Using moored or towed instruments to derive photosynthetic rates (Figure 4), net oxygen production can be derived for a given volume of ocean water. If such production exceeds respiratory demands, carbon has been fixed in excess of the steady-state levels; the "surplus" carbon must be exported or sequestered. Conversely, if oxygen production balances, or is less than respiratory demands, carbon cannot be exported. DOE developed OMP as an integrated multidisciplinary research program to examine carbon and oxygen budgets from a variety of continental margins with contrasting anthropogenic loadings to quantitatively derive the effects of these loadings on the global carbon cycle. The initial phase focusses on the Western North Atlantic continental margin where such loadings are higher than in any other ocean margin in North America.

One of OMP's major objectives is to obtain a quantitative understanding of the basic environmental regulation of the biologically and physically mediated oxidation, reduction, and transport of carbon. On geological time scales, these processes determine the outcome of the competition for the burial and oxidation of organic carbon in the ocean. This outcome, and an understanding of the factors which determine it, simultaneously determine the present-day role of ocean margins in the global carbon cycle, and provide insight into how this competition was regulated in the geological past and is predicted in the climatological future.

The information generated by this program will be used to constrain and close the global carbon cycle and explain coupied biogeochemical processes. This is a key element in developing a comprehensive carbon cycle model as part of the U.S. Global Change Research Program.

\section{Experimental Approaches to Constraining the Continental Margin Carbon Cycle}

To simultaneously obtain insights into the mechanisms controlling net carbon sequestration while quantitatively estimating the carbon sequestered requires experimental approaches which encompass a broad range of space- and time-scales (Figure 5). The biogeochemical oxidation-reduction of carbon is a consequence of biological molecular processes. Understanding on the intermediate scales of individual organisms and biological communities is crucial to interpreting the sources of variability inherent in all ecosystems. Integrating all processes occurs on the scale of complete ecosystems, which can be described with geochemical and remote sensing information, but require subscale information for interpretation. 


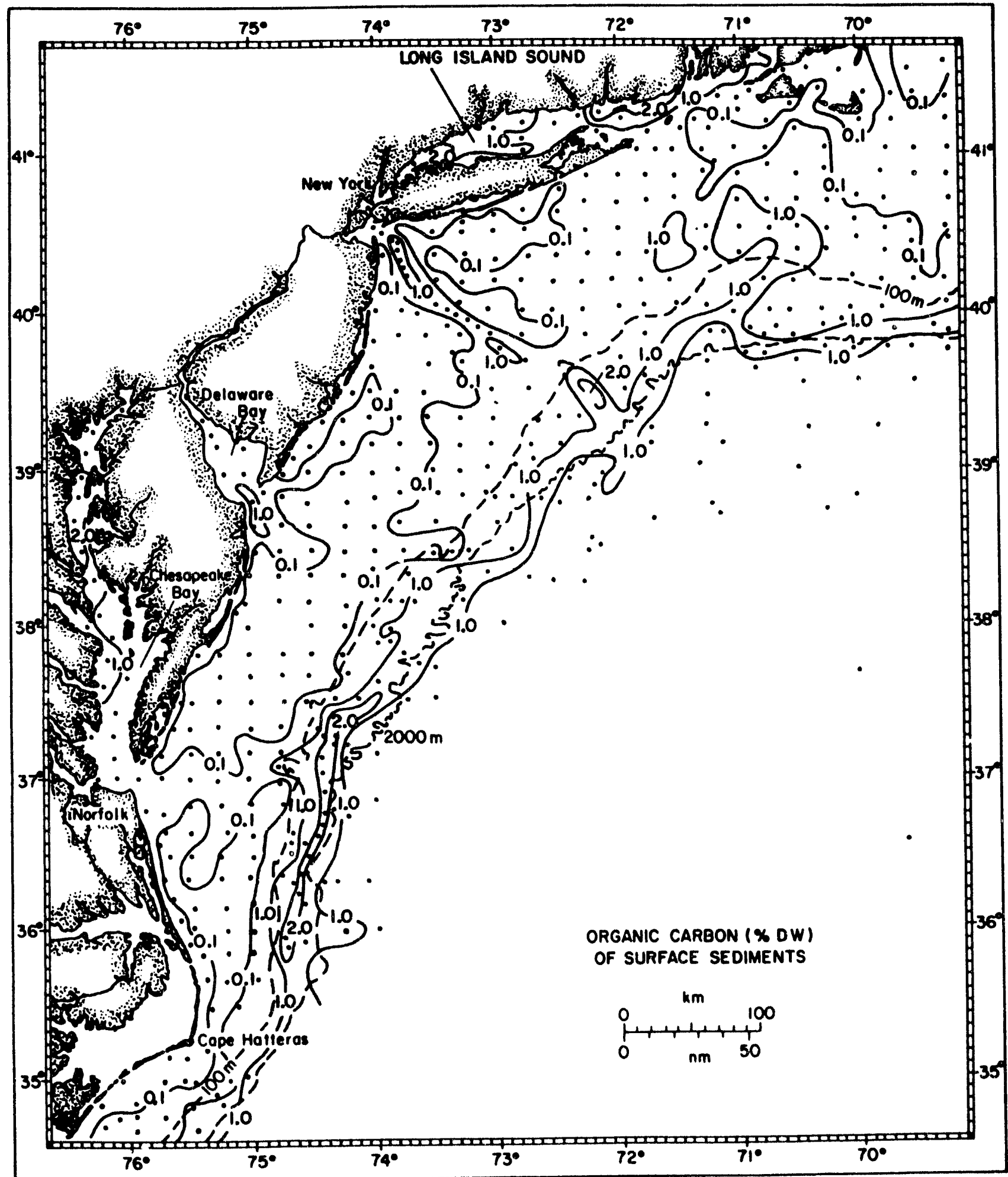

Figure 2. The distribution of organic carbon (\% dry weight) within surficial sediments of the Mid-Atlantic Bight from 1962 to 1982. [Data from Hathaway, WHOI Technical Report 71-15 (1971) and Walsh et al., Nature 291: 196 (1985).] 

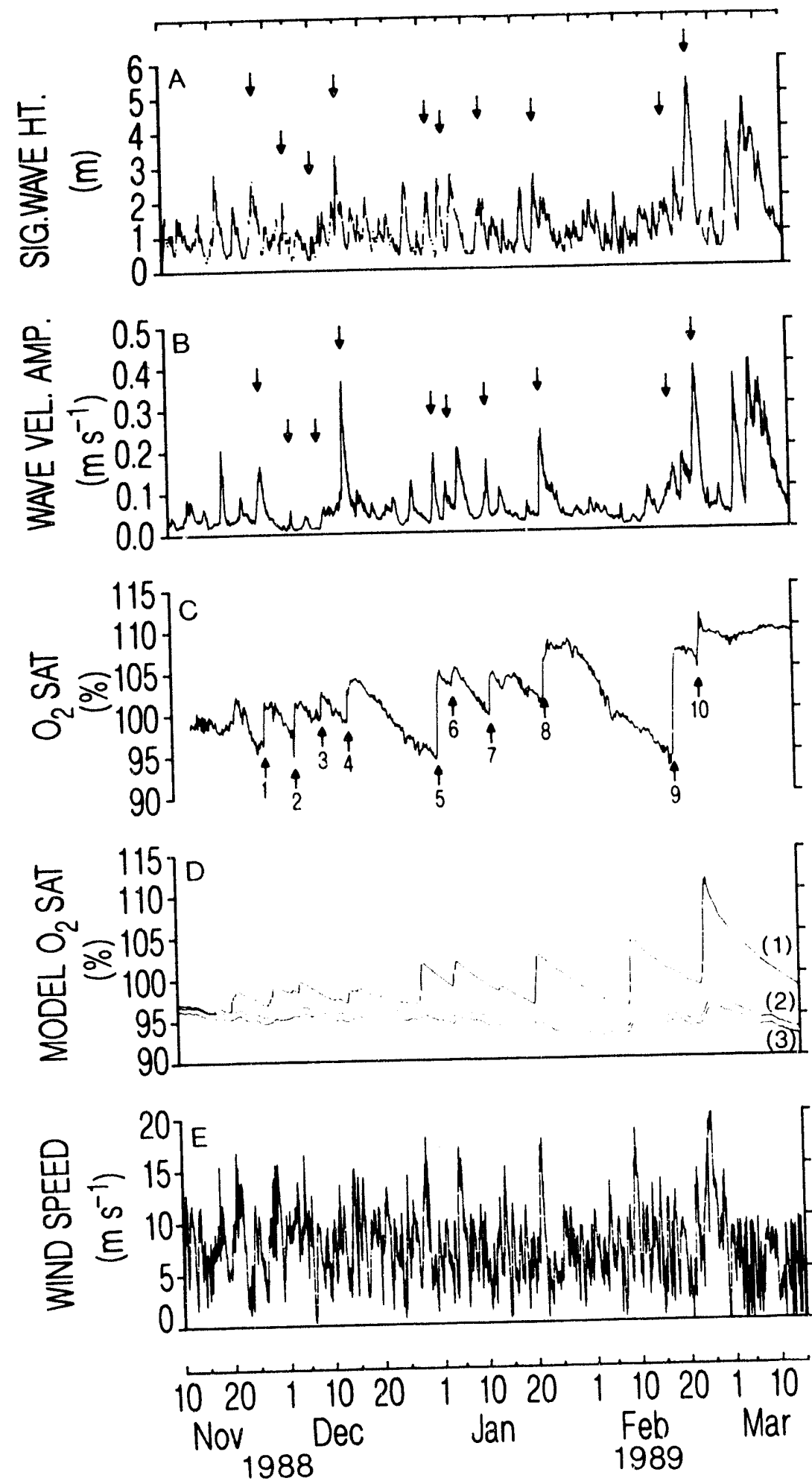

Figure 3. Observed and modelled time series from November 1988 to March 1989. Oxygen saturation at $19 \mathrm{~m}$, wave velocity amplitude, wave height, and wind speed were measured in the Mid-Atlantic Bight near the $40 \mathrm{~m}$ isobath. The 10 events of rapid increase in oxygen saturation reflect increased air-sea flux of oxygen [after Wallace and Wirick, Nature 356: 694 (1992)]. 
GYRE - G6 - 93
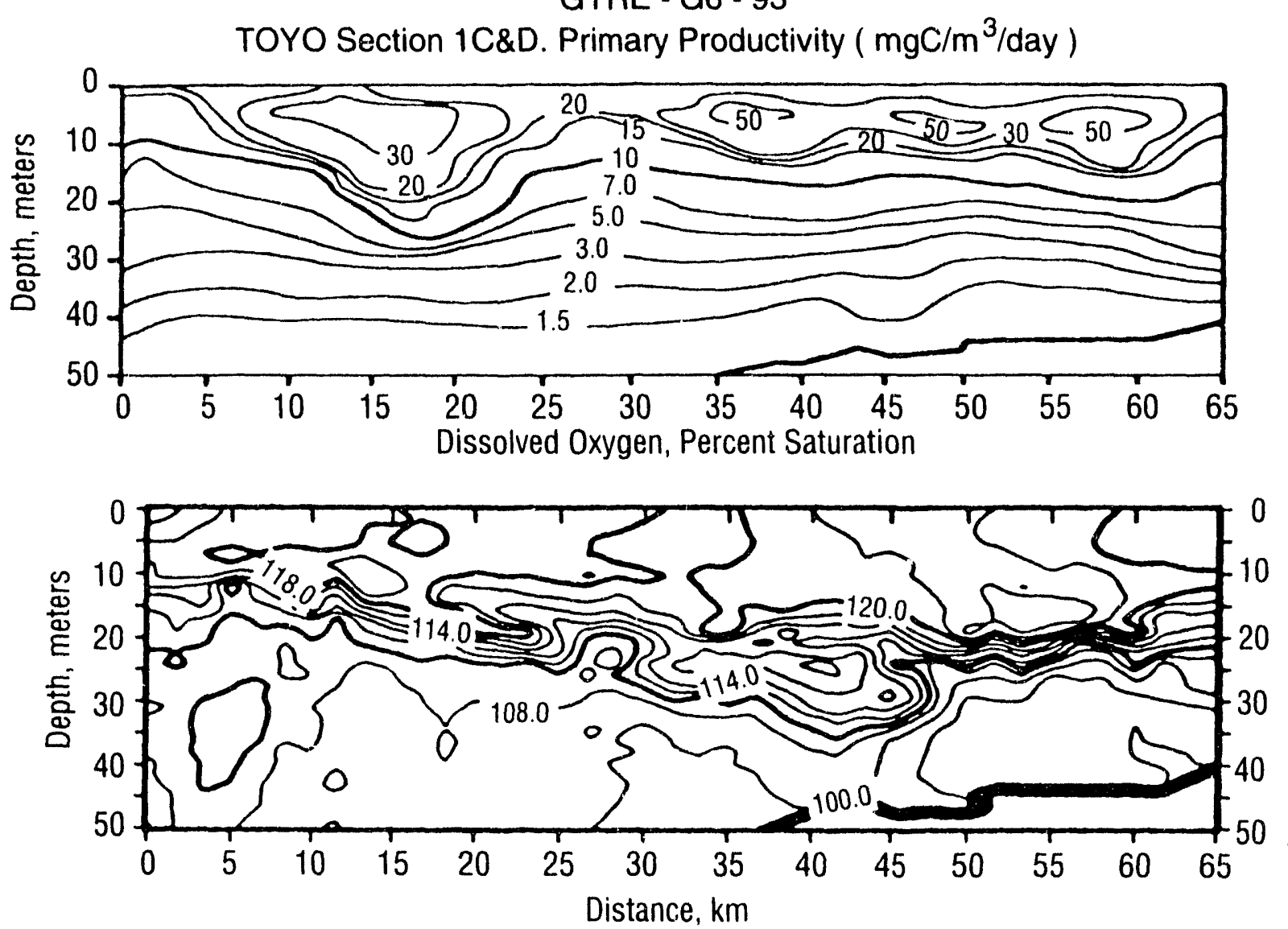

Figure 4. Primary production and dissolved oxygen measured in the Mid-Atlantic Bight in May 1993 using a towed instrument package. Primary production was calculated from Fast Repetition Rate fluorescence measurements of the photosynthetic parameters and the observed irradiance [Kolber, Z. and Falkowski, P.G., Limnol. Oceanogr. 38: 1646 (1993)].

The following specific measurements encompass the range of important scales:

- Molecularbiological and biophysical measures of carbon oxidation and reduction, and the biological control and limitations of these processes.

- Measurements of the flux and the rate of carbon oxidation and reduction of individual organisms and communities of organisms using ship-based and moored instrumentation, focussing on oxygen budgets, with sufficient measurements to account for the principal heteroge- neities that occur within each particular region.

- Geochemical tracers, including stable and radioactive isotopes and organic biomarkers that integrate numerous individual processes to give estimates of net carbon oxidation, reduction, and fluxes.

- Remotely sensed parameters, including the color, temperature, optical properties of the surface ocean and atmospheric optical properties in the continental margins as they affect biogeochemical processes. 


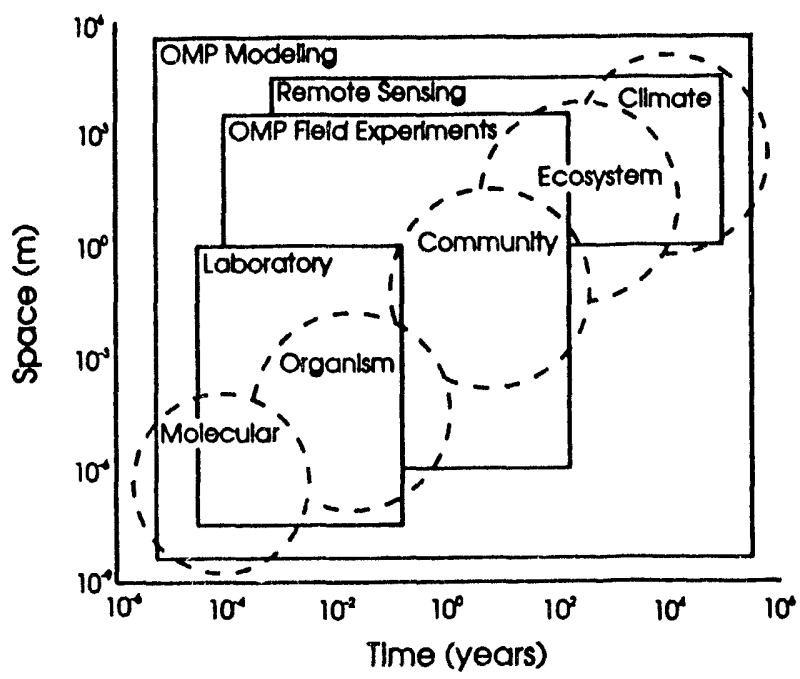

Figure 5. OMP experimental approaches to constraining the continental margin carbon cycle. Biogeochemical oxidation and reduction of carbon is a consequence of biological molecular processes which occur at small time and length scales. These processes can be directly measured in regional field experiments by using integrating variables like oxygen. Assessing carbon cycling on continental margins and predicting its affect on climate requires that field measurements and remotely sensed observations be integrated using models.

The contribution of each of these elements to OMP is described below:

\section{Molecular Biological and Biophysical Mea- surements in OMP}

There is considerable basic knowledge from model organisms about the major metabolic pathways and the types of biological regulatory processes at the genetic level. The application of this knowledge directly to real-world situations will significantly enhance understanding of the biological regulation of biogeochemical processes. The information generated by molecular biologists, structural biologists, and biophysicists supported by the Office of Health and Environmental Research and, more broadly, within the Department of Energy, has vast potential to resolve many of the environmental problems that concern DOE and the United States. Such basic research has a large application in understanding how key specific biological processes, such as photosynthetic carbon reduction and respiratory carbon oxidation, are regulated at fundamental genetic levels. Successful application of these basic tools to environmental research can lead to a further understanding of why organisms are successful in their singular environments, and of their evolutional success and environmental constraints. Presently, such understanding is elusive, but it is essential to predicting the future fate of organisms, even assuming accurate, predictive models of global climate change can be developed.

The initial scope of the molecular ecology effort in OMP is limited to the carbon cycle and the factors which control it in the coastal ocean. Carbon is the common currency of ecosystems, and chemically, the carbon cycle can be broken down into two processes, reduction and oxidation. Photosynthetic carbon fixation is a coupled oxidation-reduction process in which the electrons and protons extracted from water are used to reduce $\mathrm{CO}_{2}$. The waste product is oxygen, and this waste product, produced by photosynthetic organisms in the ocean, is the original source of all atmospheric oxygen. Continental margins are the most efficient photosynthetic areas in the ocean, and the factors that limit photosynthesis there appear to be nutrients other than $\mathrm{CO}_{2}$, which are added to the ocean as the result of human activities. The energy used to reduce $\mathrm{CO}_{2}$ is, in effect, stored solar energy, a small fraction of which has been preserved on Earth as fossil fuel. The fact that this energy was stored reveals that the photochemical reduction of carbon has exceeded 
its rate of oxidation over hundreds of millions of years.

Various molecular biological and biophysical techniques will be used to identify and quantify carbon reduction and oxidation processes in the OMP. Initially these will include the following:

1) Molecular control of gene expression of carbon-fixing enzymes in oceanic photosynthetic organisms.

2) Rezulation of photosynthetic energy conversion, a measure of the rate at which light energy is converted to chemical energy.

3) Determination of the specific nutrients which limit or control photosynthetic carbon reduction using molecular diagnostic markers.

4) Development of molecular approaches to understand the biological control of carbon oxidation.

Pools and Flux Measurements: Organism to Ecosystem

Determining the pools of carbon and the rate of carbon fixation and oxidation in the water column and benthos is complicated by physical transport. The proportion of the organic carbon that can be sequestered will depend on rates of the processes that physically transport organic materials to locations where they can be stored for long periods relative to the biological processes that rapidly reoxidize the organic carbon. Thus, a fundamental, quantitative understanding of the role of coastal waters in the carbon cycle will require knowledge of the rates of formation and oxidation of organic matter, and the mechanisms by which it is transported.

Traditional oceanographic methods for estimating rates of carbon reduction and oxidation include such measurements as radiocarbon uptake, nutrient and oxygen fluxes, and changes in the distributions and abundance of organic carbon, all of which are measured onboard a ship. Together with molecular biological studies, they can reveal how physical circulation directly and indirectly affects the abundance and distribution of photosynthetic and heterotrophic organisms on the continental margins. Among other things, physical processes determine the distribution of nutrients, vertical mixing which critically governs the exposure of phytoplankton to light, and the rate and intensity of gas exchange across the air-sea interface and the sediment-water interface. The spatial correlation of the efficiency of photosynthetic energy conversion with fronts and areas of intense mixing is one basis for relating carbon reduction to physical circulation. Physical processes strongly affect phytoplanktonic and zooplanktonic interactions that are crucial to determining the rate of oxidation of organic carbon. Therefore, one focal point for the OMP will be to elucidate the vital physical-biological interactions which determine the net new production and its fate on continental margins.

Boundary layers associated with the sea bed and sea surface are integral components of the coastal system. Because the coastal region is shallow, transformations of carbon, analogous to those occurring in the water column, occur at the sea floor. Individual processes include the primary production of organic carbon from inorganic carbon pools, transformation of organic materials by organisms of various trophic levels, and respiratory oxidation of organic carbon -returning it back to the inorganic pool. In addition, carbon accumulation in the sediments of continental margins represents the dominant mechanism for removing organic carbon from the oceans. 
Approximately half the metabolism of organic carbon within continental margins occurs in sediments. Therefore, coupled biogeochemical processes and material transport studies are key components of comprehensive investigations of global ocean carbon dynamics in general, and of ocean margins carbon dynamics in particular. A benthic boundary layer component in OMP will define the requirements for intensively measuring and sampling carbon cycling and transport. Major categories of biogeochemical measurements already have been identified as necessary for a comprehensive study of the carbon dynamics of the bottom boundary layer. The most pressing and pervasive component involves measuring currents, waves, and surface and bottom stress fields contemporaneously with an entire suite of studies on biogeochemical processes on the seafloor and in the water column.

Estimating the fluxes of carbon in continental shelf sediments has proved to be a non-trivial problem because of the many complex processes which influence carbon cycling at the sediment/water interface. These complications arise from bottom currents, the resuspension of sediment, the remineralization of carbon, and diagenetic reactions. Understanding how these processes influence the magnitude of carbon storage within the oceans' margins is crucial to accurately assessing carbon cycling in the coastal ocean.

Geochemical and Biogeochemical Processes: The Integrated System

On a large scale, mass balances and the changes in the proportions of organic and inorganic carbon pools integrate the physical and biogeochemical processes. While one variable which integrates these processes is dissolved oxygen (see below), another involves analyses of natural distributions of biomarkers, carbon isotopes $\left({ }^{14} \mathrm{C}\right.$ and $\left.{ }^{13} \mathrm{C}\right)$ and radionuclide forms. Each carbon molecule has an isotopic "signature" which is determined by its age and source function, and by the fractionation pathways involved in its transformation. Photosynthetic pathways of carbon reduction in phytoplankton feed simple organic carbon skeletons to a series of metabolic pathways. These molecules are further modified as phytoplankton and metibolized by heterotrophic consumers. The death and initial degradation of organisms generally reduces the size of the molecular aggregates, forming colloids and soluble organic materials and leading to isotopic fractionation. The total mass of colloidal and dissolved organic carbon is significantly larger than the POC contained in marine organisms, but because the volume of the water containing them is so large, the absolute concentration of individual organic molecules is extremely small. Less than $25 \%$ of the total dissolved or colloidal organic carbon has been characterized. Each organic molecule has an isotopic "signature" which is determined by isotope fractionations in the pathways of its formation and degradation. Terrestrial organic carbon sources can be differentiated from marine sources by their molecular composition and by the fact that they are frequently enriched in ${ }^{12} \mathrm{C}$ relative to ${ }^{13} \mathrm{C}$ compared with marine organic carbon. In addition to carbon isotopic tracers, marine phytoplankton also contain suites of organic molecules which are differentiable from organisms derived from estuarine or river environments. These differences can be analyzed by gas-chromatography, massspectrometry (GC/MS) methods to determine the stable isotopic composition of specific target molecules, such as amino acids and porphyrins. 
The oxidation rate of organic carbon strongly depends upon the molecular structure of the complex. The bond energy contained in some molecules is so large that they resist most oxidative reactions and persist in the environment for thousands or even millions of years. Thus, determining the age and turnover of dissolved organic matter in the sea is complicated by the poor characterization of the organic matter. In OMP, several other techniques have been used to characterize the colloidal and dissolved organic matter in the water column and sediment, in an effort to determine the origin, turnover, and fate of these important carbon pools. Analysis of naturally produced and thermonuclear derived radioactive isotopes, such as ${ }^{14} \mathrm{C}$, in the organic matter, serves as long-term and short-term biogeochemical clocks, which can be used to infer transformation rates of the organic matter. High-precision radiocarbon analyses of DOC pools, for example, using accelerator massspectrometry, will be used to (1) estimate the age and turnover of DOC; $(2)$ analyze phytoplankton pigments in sediments and surficial waters to assess the timing and turnover of POC delivered to the benthos and the pathways of remineralization; and (3) determine the adsorption and reactivity of DOC to mineral particles, a knowledge of which is crucial for deriving the storage capacity of organic carbon in the sediments.

\section{Field Techniques}

\section{Sampling and the Problems of Temporal and Spatial Heterogeneity}

Numerous factors limit the accuracy of estimates of carbon fluxes across system boundaries. A general lack of analytical precision and accuracy in measurements has hampered evaluations of pool sizes, particularly organic carbon pools. To make any progress at all, we must assume that such analytical protlems will be resolved in time. When all relevant carbon pools can be accurately and precisely measured so that important temporal and spatial differences can be discerned, then we must contend with the movement of carbon masses across the various boundaries constraining the system. The important questions to be answered next by the OMP are: a) Can adequate spatial and temporal studies of water movement across the various boundaries be achieved?, and b) If so, can average water-movement terms be established to cover the appropriate time-scales? These questions address the problem of sampling.

Spatial heterogeneity can be described using spatial statistics that then can be used to design sampling schemes capable of resolving the heterogeneity to a specified precision. Existing monthly climatologies for the distribution of properties on the continental margin of the Western North Atlantic describe the system with a crossshelf resolution of $50-100 \mathrm{~km}$, and provide a first-order description, accounting for $\sim 50 \%$ of the annual spatial variance. The remaining $50 \%$ of the annual spatial variance cannot be predicted without additional measurements which the OMP plans to make.

Transport of organic matter may occur on a variety of spatial and temporal scales. Strong mean currents may near-continuously export particulate and dissolved organic materials to the open ocean. Dispersive processes that occur in continental margin regions also may contribute to the net transport of materials where concentration gradients exist. Conversely, episodic events, such as storms, may carry massive amounts of shelf-produced organic materials to the open ocean over very short intervals. Thus, 
studies must be conducted on several temporal and spatial scales to evaluate quantitatively the transport of materials in the coastal ocean system. This approach miust include studies over large distances (i.e., an entire continental margin) to evaluate mean concentration gradients, over small spatial and temporal scales to evaluate dispersive exchanges, and over long periods at high frequency to assess infrequent but intense episodic events, as well as the small-scale dynamics of circulation that comprise the final result. Such studies will require the combined inputs from shipboard process studies and measurements, continuous measurements from moored instruments, and remotely sensed information.

\section{Ship-based Measurements}

Ships provide a platform for sampling the ocean, conducting process studies, and towing instrument packages. The spatial heterogeneity of the property distributions near Cape Hatteras has been characterized on several occasions by towitig undulating measurement systems from ships. The resulting cross-shelf sections are the highest resolution characterization possible with existing technology. Spatial statistics from these sections have been used to predict the efficiency and expected errors of less dense sampling schemes. We believe that the major spatial variations in the distributions of temperature, salinity, chlorophyll, zooplankton, and oxygen can be resolved to within $20 \%$ by moorings spaced $15-20 \mathrm{~km}$ apart. Existing information can be used to define sampling schemes that resolve the properties and processes near Cape Hatteras with specified resolution. High-frequency, small-scaled, intensive measurements from ships can be used to discriminate critical dynamics that cannot be effectively resolved from moored systems.
Observations from Continuous Moored Instruments

To relate the ship-based measurements to large-scale changes, OMP will use observations from moored instruments. Estimates of advective fluxes in the ocean's biological and chemical properties require continuous paired measurements of advection and property concentrations. High-resolution measurements of advection can be made routinely using current meters, but only a few chemical and biological properties can be measured continuously. Such measurements include photosynthetically active radiation, oxygen, total $\mathrm{CO}_{2}, \mathrm{pCO}_{2}$, phytoplankton chlorophyll, instantaneous photosynthetic rates, community respiration, zooplankton, suspended solids, and nitrate. The OMP will use this capability to measure the advective flux of phytoplankton and zooplankton carbon, suspended solids, oxygen, and total carbon dioxide.

In the OMP Phase I field program, a mooring array will be used to evaluate transport along and across the shelf. A major focus of this mooring array will be to quantify the fluxes of oxygen, which can be measured with high precision over long periods using commercially available pulsed oxygen electrodes. Past experience with these instruments in long-term (15 months) moorings opened the possibility for using oxygen measurements to develop an integrated budget for the sources and sinks of carbon on the ocean margins. Moreover, these instruments allow continuous measurements of near-surface gases that will indicate when the air-sea exchange of gases varies. This exchange is critical to developing closure on the global carbon cycle, and is poorly constrained in high-energy environments such as the ocean margins. The capability of precisely assessing gas 
exchange from moored instruments is developing, and the OMP is an ideal testbed for evaluating new methodologies and instruments.

The mooring array will also include current meters, conductivity and thermistor chains, designed to measure parameters relevant to physical processes; bottom tripods, to address bottom boundary layer processes; meteorological buoys, used to quantify air-sea momenta; and Acoustic Doppler Current Profilers (ADCPs) used to derive both vertical velocity structure and zooplankton biomass distributions. In addition, moored fluorometers will measure phytoplankton biomass and photosynthetic rates. In conjunction with the moored oxygen sensors, the suite of moored measurements will be used to budget biological sources and sinks of carbon, and differentiate these from physical transport processes.

\section{Remote Sensing}

One of the most powerful tools to emerge in oceanography has been satellite remote sensing. Satellite observations have afforded a synoptic, large-scale view of upper-ocean phytoplankton chlorophyll, seasurface temperature, surface winds, precipitation, and deformational topographic features (Table 1).

The concentration of phytoplankton chlorophyll can be derived from variations in ocean color. The next generation of ocean color sensors, including the NASAbased SeaWiFS, will allow global observations once every three days, with a resolution of $0.8 \mathrm{~km}$. In the context of the OMP, the sensors aboard SeaWiFS potentially allow spatial integration of ship-based and moored measurements of chlorophyll and primary productivity. These measurements would give continuous, quantitative estimations of the abundance and spatial distribution of phytoplankton from remotely sensed ocean color and, moreover, interrelate the in situ point measurements to local and remote ocean circulation.

Sea-surface temperature (SST) can be derived from NOAA AVHRR satellite sensors, which passively detect outbound long wavelength radiation on a $1.1 \mathrm{~km}$ grid more than four times per day. The thermal structure of the sensors provides direct information about the areal extent and mixing of water nlasses, air-sea heat exchange, and interannual climatological variations in the North Atlantic Ocean. Extrapolation of the surface-ocean thermal structure to the water column allows a reconstruction of the threedimensional thermal field as a function of time for the continental ocean margin, which can be used to infer the temporal and spatial distribution of nutrients and phytoplankton productivity.

Surface wind stress is a crucial parameter in estimating the fluxes of gases, such as $\mathrm{CO}_{2}$, between the atmosphere and ocean that can be inferred directly from satellite-based scatterometer radar systems. These data, along with in situ measurements of $\mathrm{pCO}_{2}$ in the upper ocean, can be used to delimit our estimates of carbon exchange between the atmosphere and ocean.

Precipitation, which critically determines the interaction of coastal shelf waters with the open ocean, is notoriously difficult to measure in situ. This parameter can be retrieved from active radar and microwave imaging, which also allows us to analyze raindrop size. The latter is of special interest in assessing the importance of anthropogenic aerosol sulfate pollution to the latent and sensible heat balances of the 
Table 1. Remote Sensing Systems Potentially Usable in OMP

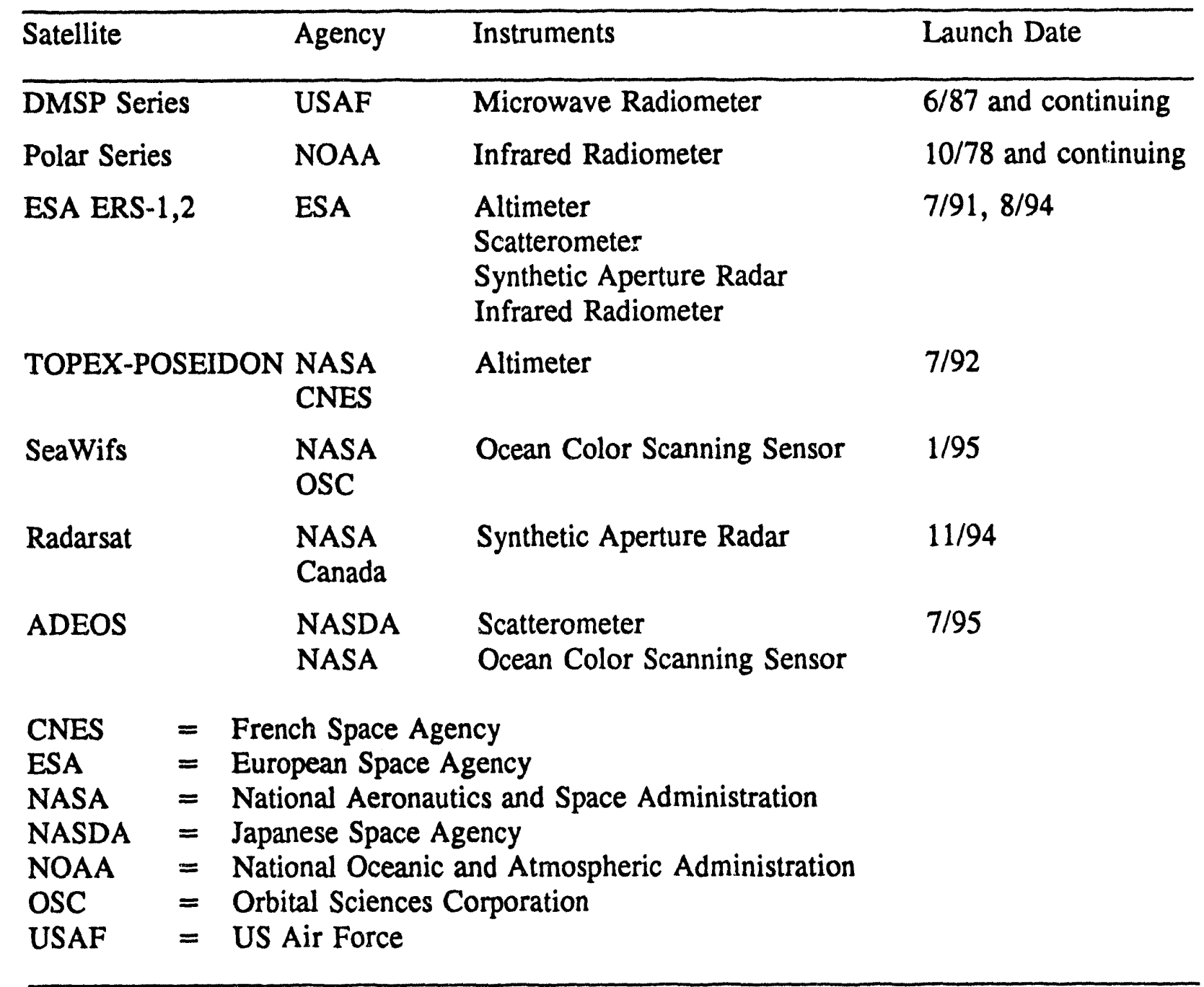

ocean-atmosphere system. The interaction of the large evaporative flux of water vapor with anthropogenic aerosol sulfate conspires to produce high albedo, low altitude clouds along the east coast of the United States. Near Cape Hatteras, where the Gulf Stream diverges from the coast, and the continentocean thermal contrast is high, is an ideal environment for the genesis of marine stratus clouds. The anthropogenic sulfate flux may be enhanced further by the outgassing of natural organosulfate compounds, produced by phytoplankton in the coastal ocean. Compound remote sensing of ocean color, cloud albedo, and wind fields potentially provide an avenue for differentially extracting the anthropogenic forcing from the overall signal. Such forcing is important in determining the negative feedback of greenhouse gases on potential global warming.

\section{Integration of Information}

Integrating information from various scales will result in a better understanding of the role of the ocean margins in the global carbon cycle, and will lead to the development of a rational societal and economic 
energy policy relevant to DOE. To inte. grate the process studies, OMP will make use of dissolved $\mathrm{O}_{2}$, biogeochemical tracers, and the long-term global monitoring efforts already underway in many countries and by a number of Federal agencies in the U.S., to develop a mathematical, simulation modeling effort. This modeling effort will provide a pathway for linking OMP to the coupled atmosphere-ocean circulation modeling efforts underway in DOE and NOAA, thereby allowing predictive and quantitative analyses of the effects of anthropogenic influences on global biogeochemical cycles and their climate feedbacks.

While modeling provides a framework for integrating scientific information, the regional information derived by OMP will not lead directly to a global model. As the Phase I field program winds down in 1997, a comparison of the results obtained from the Western North Atlantic study with other margin settings which differ in their fundamental characteristics will begin. Logical, comparative end-members include pristine margins: (1) with narrow continental shelves adjacent to wind-driven upwelling systems, and (2) dominated by freshwater input. High latitude shelves, such as the Bering Sea, are areas with potential for comparative studies. While case studies of these settings may be adequate, OMP will critically analyze potential high-priority regions for further field research opportunities, which are needed to provide closure on the global carbon cycle.

\section{Relationship to other Ocean and Global Change Programs}

The DOE OMP is linked with other Global Climate Change Research Programs. Specifically, OMP is important to the U.S. JGOFS, GLOBEC, LOICZ, and LMER
Programs because there is compelling evidence that the input of nutrients to coastal areas from land-based sources (via rivers/ estuaries/atmosphere) and interior-ocean sources (via coastal upwelling and frontal exchange) causes as much as $50 \%$ of the total primary production of the global ocean to occur along the ocean margins. Hence, these areas may play an important role in the cycling and flux of $\mathrm{CO}_{2}$ and biogenic elements within the global-ocean. These interactions are likely to increase in the future in proportion to increases in population levels in coastal regions. The OMP and its scientific researchers also are interacting with several other U.S. Federal Agency programs concerned with quantifying the processes and fluxes that affect the transport and fate of water, carbon, nutrients, biota, sediments, and pollutants in changing estuarine and coastal environments. These agencies and programs include NOAA's FOCI, NECOP, NMFS, NURP, and SABRE Programs; NSF's Chemical Oceanography and CoOP Programs; EPA; MMS/SAIC; NASA; NRL; ONR; and the North Carolina Division of Marine Fisheries. In addition, the research within OMP is corollary to, and linked with, other DOE global-change programs that focus on ecological dynamics (PER), Greenhouse Gases and Climate (Core $\mathrm{CO}_{2}$ ), and atmosphere-ocean interactions (Ocean $\mathrm{CO}_{2}$ and $\mathrm{ARM}$ ). This program also has interacted with, and received intellectual support from, many scientists who are not directly supported by DOE.

\section{Significance of OMP to Understanding the Global Carbon Cycle}

At present, as a result of human energy-related activities, the global oxidation of stored organic carbon exceeds biological carbon fixation by about 5 GT per annum. Consequently, the atmosphere is becoming 
increasingly enriched with $\mathrm{CO}_{2}$, which potentially can change radiative forcing and climate. However, importantly, the global carbon budget is not well constrained. Approximately $2 \mathrm{GT}$ of carbon added to the atmosphere each year cannot be accounted for, and what this sink is remains unclear. Estimates of photosynthesis vary by more than $25 \%$, but are approximately 100 GT per annum. Although carbon fixation in the ocean is thought to account for about $40 \%$ of the global total, human influences on this fixation rate are unknown. Anthropogenic effects are almost certainly totally constrained to the continental margins. This region of the ocean has been largely dismissed by modelers because it represents a non-steady state boundary condition, and by geochemists because there is inadequate data for evaluating the margins' importance.
The rate of nutrient enrichment of the ocean margins resulting from human population growth is unknown but large and increasing; it is significantly underestimated from measurements of dissolved inorganic nutrients alone, as they do not include the large pools of nutrients represented by dissolved and particulate organic materials. The overall goal of the OMP program, to understand the role of the continental ocean margins in the absorption and sequestration of anthropogenic carbon, will provide ciusure on the global carbon cycle. In so doing, this program will provide an understanding of the effects and consequences of human energyrelated activities on the function, productivity, and viability of the coastal ocean margins for future generations of Americans, who will increasingly be forced to manage sustainable ecosystems and develop renewable energy sources. 


\section{Glossary of Acronyms}

$\begin{array}{ll}\text { ARM } & \text { Atmospheric Radiation Measurements Program } \\ \text { CENR } & \text { Committee on Environment and Natural Resources } \\ \text { CNES } & \text { French Space Agency } \\ \text { CoOP } & \text { Coastal Ocean Processes } \\ \text { DOC } & \text { Dissolved Organic Carbon } \\ \text { DOE } & \text { Department of Energy } \\ \text { EPA } & \text { Environmental Protection Agency } \\ \text { ESA } & \text { European Space Agency } \\ \text { FOCI } & \text { Fisheries Oceanography Cooperative Investigation } \\ \text { GLOBEC } & \text { Global Ocean Ecosystem Dynamics } \\ \text { JGOFS } & \text { Joint Global Ocean Flux Study } \\ \text { LMER } & \text { Land Margin Ecosystems Research Program } \\ \text { LOICZ } & \text { Land-Ocean Interactions in the Coastal Zone } \\ \text { MMS } & \text { Minerals Management Service } \\ \text { NASA } & \text { National Aeronautics and Space Administration } \\ \text { NASDA } & \text { Japanese Space Agency } \\ \text { NECOP } & \text { Nutrient Enhanced Coastal Ocean Productivity } \\ \text { NMFS } & \text { National Marine Fisheries Service } \\ \text { NOAA } & \text { National Oceanographic and Atmospheric Administration } \\ \text { NRL } & \text { Naval Research Laboratory } \\ \text { NSF } & \text { National Science Foundation } \\ \text { NSTC } & \text { National Science and Technology Council } \\ \text { NURP } & \text { National Underwater Research Program } \\ \text { OMP } & \text { Ocean Margins Program } \\ \text { ONR } & \text { Office of Naval Research } \\ \text { OSC } & \text { Orbital Sciences Corporation } \\ \text { PER } & \text { Program for Ecosystems Research } \\ \text { POC } & \text { Particulate Organic Carbon } \\ \text { SABRE } & \text { South Atlantic Bight Recruitment Experiment } \\ \text { SAIC } & \text { Science Applications International Corporation } \\ \text { USAF } & \text { United States Air Force } \\ & \end{array}$



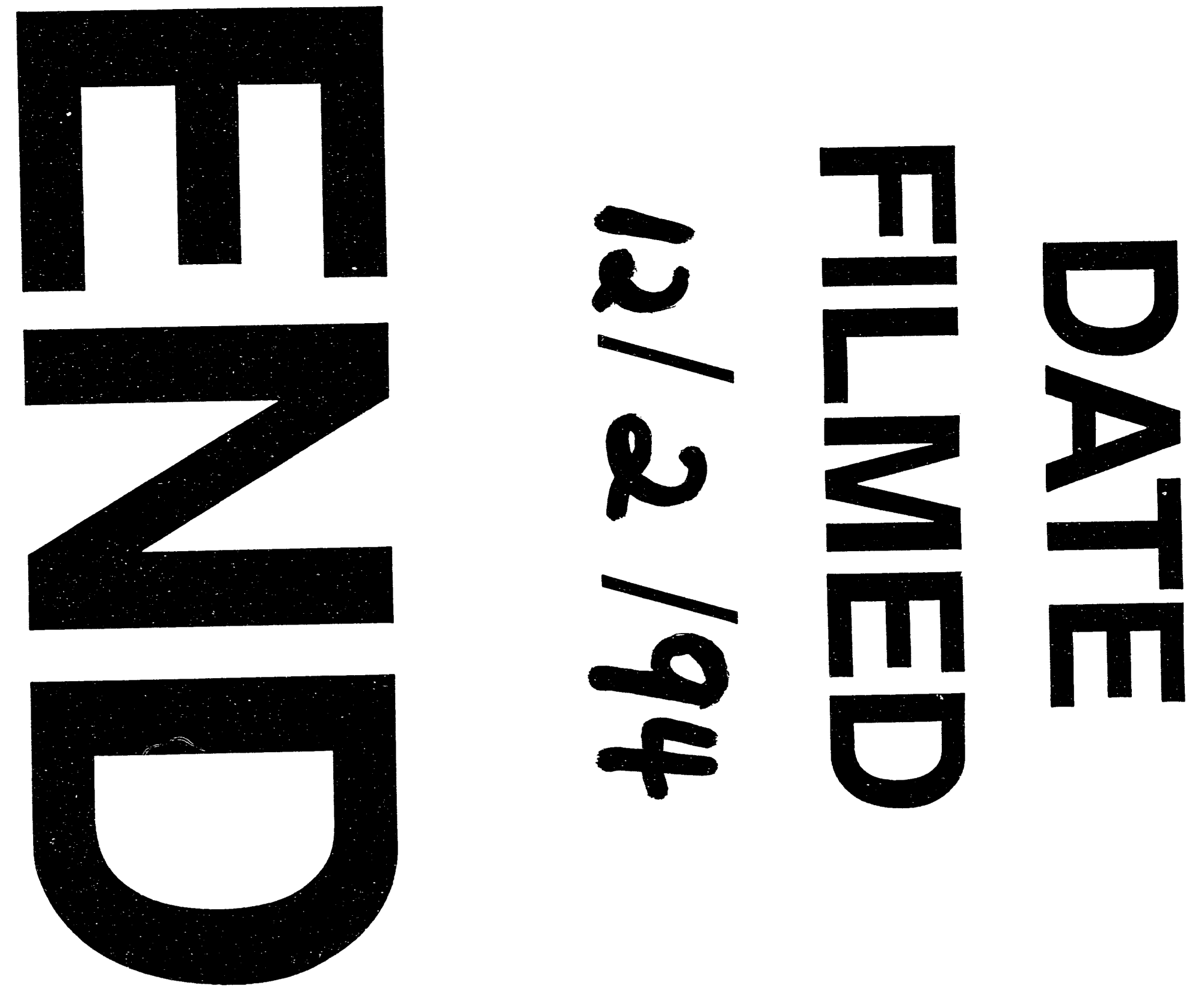